\title{
Endonasal Endoscopic Excision of Juvenile Nasopharyngeal Angiofibroma- The Technical Difficulties \& Advantages
}

\author{
BISWAS SS ${ }^{\mathrm{a}}$, AMIN ZA $^{\mathrm{b}}$, CHAKRABORTY R $^{\mathrm{c}}$, MAHBUB S $^{\mathrm{d}}$, HALDER $^{\mathrm{e}}$
}

\begin{abstract}
:
Objective: Endoscopic excision of juvenile nasopharyngeal angiofibroma (JNA) was carried out with the objective of minimizing blood loss and attempting to complete excision of tumor under direct vision with the help of Hopkins telescope.
\end{abstract}

Study design: A retrospective 12 year study of 6 cases of JNA treated by endoscopic excision is presented.

Result: According to Radkowski's classification, two patients were stage Ia, two were stage Ib and two patients were stage IIb. The mean duration of the surgery was 2 hours. The mean intra-operative blood loss was $575 \mathrm{ml}$. The mean follow -up after the primary operation was 23.3 months. All the

\section{Introduction:}

JNA is a relatively rare benign vascular neoplasm that arises at sphenopalatine foramen of the nasopharynx affecting primarily adolescent males. ${ }^{1}$ JNA accounts for only $0.05 \%$ of all head $\&$ neck tumours ${ }^{2}$. Its propensity to bleed torrentially is due to its highly vascular nature.

a. Dr. Sudhangshu Shekhar Biswas, MBBS, DLO, FCPS (ENT), Assistant Professor, Dept. of Otolaryngology \& HeadNeck Surgery, BIRDEM General Hospital \& Ibrahim Medical College

b. Prof. Zaheer Al- Amin, MBBS(Dhaka), DLO(England), FRCS(Ireland), FRCS (Edin, UK), Professor \& Head, Dept. of Otolaryngology \& Head-Neck Surgery, BIRDEM General Hospital \& Ibrahim Medical College

c. Dr. Rajashish Chakrabortty, FCPS (Medicine), MD (Chest), Assistant Professor, Respiratory Medicine, BSMMU, Dhaka

d. Dr. Shawhely Mahbub, MBBS, DLO, FCPS(ENT), Senior Medical officer, Dept. of Otolaryngology \& Head-Neck Surgery, BIRDEM General Hospital

e. Dr. Soma Halder, MBBS, Department of Paediatrics, BSMMU, Dhaka

Address of correspondence: Dr. Sudhangshu Shekhar Biswas, MBBS, DLO, FCPS (ENT), Assistant Professor, Room:103, Dept. of Otolaryngology \& Head-Neck Surgery, BIRDEM General Hospital \& Ibrahim Medical College, E mail: b.sudhangshu @yahoo.com Mobile no: 01817049310

Received: 02, May, $2013 \quad$ Accepted: 10 February, 2014 patients but one were free of disease. One patient had a recurrence in the pterygopalatine fossa requiring a successful revision procedure 3 years after the primary surgery.

Conclusion: Endoscopic resection of JNA is a difficult but effective operation in experienced hands. The endoscopic management had less intra operative blood loss, lower occurrence of complications, shorter length of hospital stays and lower rate of recurrence. So it should be considered as a first choice option.

Key words: Juvenile Nasopharyngeal angiofibroma, endonasal surgery, endoscopy

(Birdem Med J 2014; 4(2):74-78)

Histologically, the tumour is unencapsulated and consists of wide spaces lined by a single endothelial layer. These channels are surrounded by a collagenous tissue network and lack a complete muscular layer that result in easy bleeding. It can spread to involve nasopharynx, parapharyngeal spaces, nasal cavity, paranasal sinuses, infratemporal fossa, orbit and middle cranial fossa that makes it clinically a rather feared entity. ${ }^{3}$ Surgery is the preferred mode of treatment, radiation being reserved for unresectable intracranial tumors ${ }^{4}$. The various surgical approaches that have been tried previously e.g. transpalatal, lateral rhinotomy, Weber Fergusson, midfacial degloving and the trans-zygomatic infratemporal approachs reflect clearly the technical difficulty in completely excising all tumor extensions . The open approaches result in extensive morbidity, tissue loss and disfigurement to the patient ${ }^{5}$.

\section{Aims \& Objectives:}

The purpose of this study was to determine whether the endoscopic approaches had less per operative blood loss, shorter duration of hospital stay, less chance of complications, lower rate of recurrence, no requirement of nasal packing and no chance of any facial scar as compared with traditional surgical approaches. 

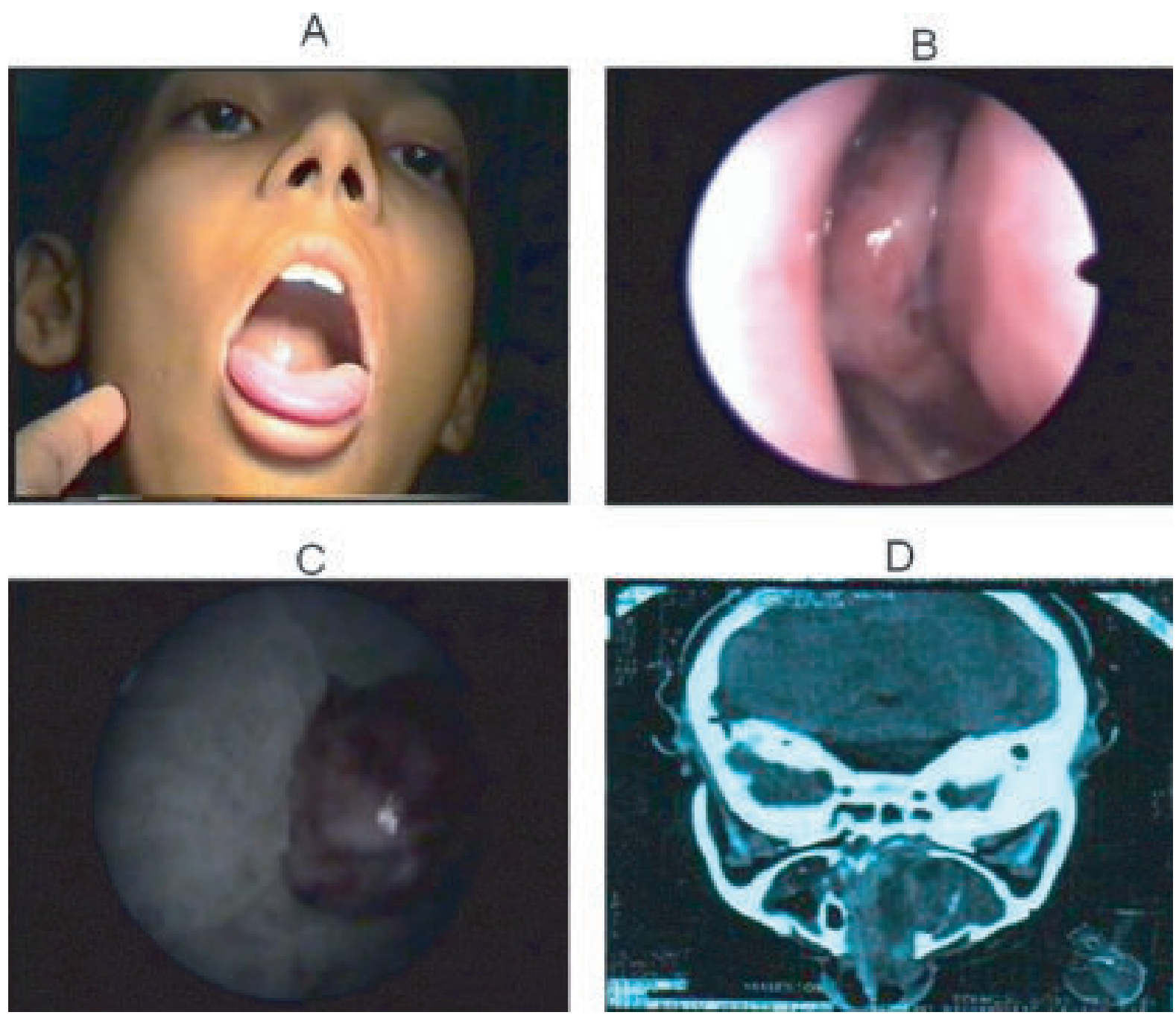

Figure : (A) clinical view soft palate bulging of angiofibroma (B) endoscopic view of typical angiofibroma a at the posterior part of the left nasal fossa (C) macroscopic view of surgical specimen (D) axial CT scan extention of the angiofibromaa into the left sphenoid sinus and left nasal cavity.

\section{Materials \& Methods :}

From 2000 to 2012, 6 consecutive patients with extracranial JNA had been operated on with a pure endonasal endoscopic approach in the department of Otorhinolaryngology of BIRDEM General Hospital. Persistent nasal obstruction with recurrent nasal bleeding was the major symptoms in all cases. No associated otological, ophthalmological or neurological symptoms were reported. All patients had a complete preoperative evaluation including a nasal endoscopy, a computerized tomography (CT) scan with contrast, a MRI \& a selective angiography of both internal \& external carotid systems. The tumour involved the nasopharynx in all cases (6/6), the sphenoid sinus (3/6), $\&$ medial part of pterygomaxillary fossa (4/6).

\section{Surgical Techniques :}

Maxillary antrostomy, sphenoidectomy and ethmoidectomy are the routes of better surgical accesses to remove the tumour of JNA completely or to debulk the tumour mass from nasopharynx \& its surroundings. The pterygopalatine fossa is accessible by removal of posterior wall of maxilla by bone punches and drilling the posterior wall. In this anatomical region the tortuous 
maxillary artery can be ligated by using vascular clips endoscopically. Blunt dissection is helpful in separating the tumour from surrounding tissues ${ }^{5}$. The spreed of tumour mass into the orbit, pitutary fossa are the contraindication as suggested by some for endoscopic removal of JNA. There is considerable literature showing endoscopy with magnification provides good visualization than open method ${ }^{6}$. The operation is performed under hypotensive general anaesthesia as well as head end of the patient is elevated at least $15^{\circ}$ during surgery that help considerably in minimizing the blood loss.

\section{Result:}

All the patients were male. The mean age was 14 years. The duration of the surgery varied from 1 to 3 hours with an average of 2 hours. No vascular, ophthalmological or neurological complications were reported intra-or postoperatively. The intraoperative blood loss varied from $300 \mathrm{ml}$ to $1000 \mathrm{ml}$ with a mean of $575 \mathrm{ml}$. No exogenous blood transfusion was necessary. Since the operative fields were bloodless, after complete tumor excision, no anterior or posterior nasal packing was required. The raw areas were covered with antibiotic soaked gel foam alone. The patients were monitored closely in the intensive care unit for 24 hours following surgery. The postoperative courses were uneventful. Histopathology confirmed the diagnosis of angiofibroma.

All cases achieved immediate remission of symptoms. The mean postoperative follow up after primary surgery was 23.5 months (range: 12 - 40 months), all patients were still free of disease, except one who had a recurrence of $5 \mathrm{~mm}$ nodule, in the pterygo-palatine fossa requiring a successful revision procedure 3 years after the primary surgery.

Table-I

\begin{tabular}{|c|c|c|c|c|c|c|}
\hline Patient & $\begin{array}{c}\text { Age } \\
\text { (years) }\end{array}$ & Gender & $\begin{array}{l}\text { Location of JNA \& } \\
\text { extensions }\end{array}$ & $\begin{array}{c}\text { Peroperative } \\
\text { bleeding }\end{array}$ & $\begin{array}{c}\text { Follow-up } \\
\text { (months) }\end{array}$ & Result \\
\hline 1. & 14 & Male & $\begin{array}{l}\text { Nasopharynx } \\
\text { Extension to right sphenoid } \\
\text { sinus \& medial part of the } \\
\text { pterygopalatine fossa }\end{array}$ & $1000 \mathrm{ml}$ & 40 & Free of disease \\
\hline 2. & 12 & Male & Nasopharynx & $300 \mathrm{ml}$ & 12 & Free of disease \\
\hline 3. & 19 & Male & $\begin{array}{l}\text { Nasopharynx extended to } \\
\text { sphenoid sinuses }\end{array}$ & $700 \mathrm{ml}$ & 15 & Free of disease \\
\hline 4. & 14 & Male & $\begin{array}{l}\text { Nasopharynx \& extension to } \\
\text { right nasal cavity \& } \\
\text { pterygopalatine fossa }\end{array}$ & $300 \mathrm{ml}$ & 18 & Free of disease \\
\hline 5. & 12 & Male & $\begin{array}{l}\text { Nasopharynx \& pterygomaxillary } \\
\text { fossa }\end{array}$ & $500 \mathrm{ml}$ & 24 & Nodule: $5 \mathrm{~mm}$ \\
\hline 6. & 13 & Male & $\begin{array}{l}\text { Nasopharynx with extension to } \\
\text { left pterygopalatine fossa \& } \\
\text { sphenoid sinus }\end{array}$ & $650 \mathrm{ml}$ & 32 & Free of disease \\
\hline
\end{tabular}




\section{Discussion:}

Endoscopic surgery of the nose and paranasal sinuses has gained wide acceptance over the last decade. With its evolution, better instrumentation and increasing experience in the field, it is now possible to view endoscopic excision of angiofibroma as a viable alternative or a useful adjunct to open surgery.

Although a great deal of work still needs to be done in this area, our experience indicates that complete and safe endoscopic excision of JNA is not only possible but may be the preferred method in selective tumours.

Typically, conventional open surgery has been associated with severe haemorrhage. Significant bleeding may also impede accurate visualization of tumour extension ${ }^{7}$, often resulting in residual tumour being left behind. This results in the quite frequently recorded recurrence rate of the tumour. Residual remnants of the tumour can also cause post operative haemorrhage. Thus conventionally patients operatated for JNA require tight anterior and posterior nasal packings for a period of 3-5 days. These pack, besides extremely uncomfortable for the patient, have to be removed as a second procedure usually under general aneasthesia. In young prepubescent males, surgical trauma in the facial skeleton may adversely impact the midfacial growth in the future ${ }^{8}$. Also, the presence of an external scar on the face in certain surgical approaches is a distinct disadvantage in these young boys.

Endoscopic excision of JNA ensures that every attachment of the tumour can be visualized, cauterized with a bipolar diathermy and dissected precisely. Since this dissection is done under direct vision in the plane between the tumour and the surrounding tissues, the tumour tissue itself is not breached in the process ${ }^{9}$. This ensures that the blood loss is minimum. The internal maxillary artery may tether the tumour in the infratemporal fossa. The vessel may need to be clipped or cauterized before freeing the tumour.

Surgery in a relatively blood less field under direct vision also ensures complete removal of the tumour with less likelihood of remnants being left behind. Any remnant of the tumour can be dissected endoscopically and removed after the main mass has been delivered per orally. With standard external approaches some areas still remain inaccessible to the surgeon's probing finger. One such area is the junction of sphenoid bone and the perpendicular plate of palatine bone. Tumour remnants in these areas can then be excised endoscopically at a second stage. Understandably we accept the rates of recurrence of JNA to decrease with this surgical technique. From the patient's point of view, endoscopic surgery is a far less morbid procedure. The patient has no nasal pack postoperatively and is able to breath, eat and talk comfortably, within hours of surgery. The total duration of hospital stay is considerably reduced and the absence of any facial scar is a significant advantage in these adolescent patients.

Many authors did not have any recurrence ${ }^{10}$ while others reported some ${ }^{11,12}$. In our series, we had one recurrence out of six cases, 3 years after the first surgery. Hofman ${ }^{13}$ reported 16 cases: he had 3 recurrences, 2 cases with residual disease and 11 cases free of disease. Roger and colleages ${ }^{14}$ had 2 residual diseases out of 10 patients with advanced tumour. Nicolai ${ }^{15}$ had 1 residual lesion out of 4 tumours invading either the infratemporal fossa or the parasellar region.

Relative drawbacks that we faced were: (1) increase in the intraoperative time which on an average was 2 hours. However with greater experience in this technique, it has been possible to reduce the operative time. (2) Lack of adequate space to move around large intranasal masses. (3) Severe intraoperative haemorrhage may be difficult to control endoscopically. This would entail converting the endoscopic approach to an open surgical approach.

There are certain prerequisites necessary for endoscopic surgery to be successful. (1) A good and effective preoperative embolization is necessary if endoscopic excision is to be attempted ${ }^{16}$. The ideal time to operate would be within $24-72$ hours of embolization. It is unfortunate but fact that embolization facility is not available in our country. (2) The hypotensive anaesthesia as well as head end of the patient is elevated at least $15^{0}$ during surgery that help considerably in minimizing the blood loss. (3) Before attempting endoscopic excision, all preparations for conventional open surgery if required, should be kept ready e.g. reservations of adequate blood units, preparations of surgical instrument trolley, informed written consent etc. (4) Initially we restricted this technique for tumours that were limited to the nasal cavity and paranasal sinuses with minimal extension 
into the pterygopalatine fossa. We later used endoscopic surgery for medium sized tumours involving the nasal cavity, maxillary sinus, nasopharynx, sphenoid sinus, pterygopalatine fossa also ${ }^{17}$. (5) Meticulous care and patience is required to dissect all the attachment of the tumour from the underlying bone without entering the tumour tissue itself. It may be necessary to excise the posterior part of the middle turbinate, perpendicular plate of palatine bone and medial and posterior walls of the maxillary sinus in order to visualize the complete tumour. (6) A strict follow-up protocol where the patient is assessed both endoscopically and with a CT scan with contrast / MRI should be carried out in all patients on a long term basis. Ideally if finances permit, an MRI is the preferred option at 1 year following surgery. Since very small recurrent tumours may remain asymptomatic for a longer period of time, the patients should be followed up at six monthly intervals thereafter over the subsequent years. This will ensure that recurrences are diagnosed and treated much earlier, even before they become symptomatic. With increasing experience we have began to identify prognostic indicators for predicting outcome in these difficult tumours. A poor prognosis i.e. a recurrence or incomplete removal of tumour is more likely in cases where there has been excessive bleeding, dense adhesions, involvement of the superior and inferior orbital fissures, piecemeal removal and previously operated tumours. Surgery on a recurrent tumour has a poorer prognosis as these tumours tend to have diffuse and dense adhesions, a mixed blood supply from the internal and external carotid artery systems and poor demarcation of the tumour from the surrounding tissues.

\section{Conclusion}

Endoscopic excision of JNA is safe \& effective operation $\&$ can be performed for selected lesions. Even as the results of excision of JNAs in these cases are highly gratifying, the true advantages, benefits and limitations of this approach are becoming clear only as we continue to do more cases endoscopically. We hope to see a significantly decreased patient morbidity, a decrease in recurrence rates after auditing a greater number of cases. However it indicates that endoscopic excision of JNA could be a viable, more precise and better alternative approach in comparison to open surgery in selected tumours.

\section{References:}

1. Batsakis JG. Tumors of the Head and Neck: Clinical \& Pathological Considerations, 2nd ed. Baltimor: Williams \& Wilkins, 1979: 296-300.

2. Gullane PJ, Devidson J, O’Dwyer T, Forte V. Juvenile angiofibroma: a review of the literature and a case series report. Laryngoscope 1992; 102: 928-33.

3. Neel HB II. Juvenile angiofibroma. In: BlitzerA, LawsonW. FriedmanWH, eds. Surgery of the Paranasal Sinuses. Philadelphia: W.B. Sounders Company, 1985: 247-59.

4. Ungkanont K, Byers RM, Weber RS, Callender DL. Wolf PF, Goepfert H: Juvenile Nasopharyngeal Angiofibroma: An Update of Therapeutic Management. Head Neck 1996; 18(1); 60-66.

5. Mann WJ,Jeher P.Amedee RG. Jurmei Angiofibromus; Changing surgical concept over last years. Laryngoscope 2004; 114(2): 291-293.

6. Roger G Tran Ba Huy P. Frochlich P. Exclusively endoscope removel of Juvenilc nasophryngeal angiofibroma; tenss and limits. Arch otolaryngeal head and neck surgery 2002; 128(8): 928-35.

7. Herman P, Lot G, Chapot R. Long term follow-up of Juvenile Nasopharyngeal Angiofibromas: Analysis of Recurrences. Laryngoscope 1999; 109: 140-47.

8. Shenoy AM, Grover N, Janardhan N. Juvenile Nasopharyngeal Angiofibroma: A study of recurrence pattern and role of pre-operative embolization-, 'A decade's experience'. Indian journal otolaryngology and head and neck surgery 2002; 54(4), 274-79.

9. Kamel RH. Transnasal endoscopic surgery in juvenile nasopharyngeal angiofibroma. Journal of laryngology and otology; 1996; 110: 1962-8.

10. Mitskavich MT, Carrau RL, Snyderman CH, Weissman JL, Fagan JJ. Intranasal excision of a juvenile angiofibroma. Auris Nasus Larynx 1998; 25: 39-44.

11. Jorissen M, Eloy P, Rombaux P, Bachert C, Daele J. Ensoscopic sinus surgery for juvenile nasopharyngeal angiofibroma. Acta Otorhinolaryngol Belg 2000; 54: 201-19.

12. Naraghi M, Kashfi A. Endoscopic resection of nasopharyngeal angiofibroma by combined transnasal and transoral routes. Am J Otolaryngol 2003; 24: 149-54

13. Hofmann T, Bernal-Sprekelsen M, Koele W, Reittner P, Kiein E, Stammberger H. Endoscopic excision of Juvenile Nasopharyngeal Angiofibroma- long term results. Rhinology 2005; 43: 282-89.

14. Roger G, Tran Ba Huy P, Froelich P. Exclusively endoscopic excision of Juvenile Nasopharyngeal Angiofibroma; Trends and limits Arch Otolaryngol Head Neck Surg 2002; 128:928-35.

15. Nicolai P, Barlucchi M, Tomenzoli, D Cappiello J, Trimarchi M, Maroldi R et al. Endoscopic, Surgery For Juvenile angiofibroma: when and how.Laryngoscope. 2003; 113: 775-82.

16. Tranbahuy P. Borsik M. Herman P. et al. Direct Intratumoral Embolisation of Juvenile Angiofibroma. American Journal of Otolaryngology 1994; 15(6): 429-35.

17. Fisch $U$. The infratemporal fossa approach for nasopharyngeal tumours. Laryngoscope; 1983; 93(1): 36-44. 